\title{
Internal thoracic artery grafting in the elderly patient undergoing coronary artery bypass grafting: Room for process improvement?
}

T. Bruce Ferguson, Jr, MD

Laura P. Coombs, PhD

Eric D. Peterson, MD, MPH
For the Society of Thoracic Surgeons National Database Committee and the Duke Clinical Research Institute.

Supported in part by R01-HS10603 from the Agency for Healthcare Research and Quality.

Read at the Eighty-first Annual Meeting of The American Association for Thoracic Surgery, San Diego, Calif, May 6-9, 2001.

Received for publication May 2, 2001; revisions requested July 26, 2001; revisions received Sept 7, 2001; accepted for publication Oct 29, 2001.

Address for reprints: T. Bruce Ferguson, Jr, MD, Professor of Surgery and Physiology, LSU Health Sciences Center, 1542 Tulane Ave, 7th Floor, New Orleans, LA 701122822 (E-mail: bruceferg732@pol.net; tfergu@1suhsc.edu).

J Thorac Cardiovasc Surg 2002;123:869-80 Copyright $\odot 2002$ by The American Association for Thoracic Surgery

$0022-5223 / 2002 \$ 35.00+0 \quad \mathbf{1 2 / 6 / 1 2 1 6 7 9}$ doi: $10.1067 / \mathrm{mtc} .2002 .121679$
Objective: The acute and long-term benefits of internal thoracic artery grafting are clear in younger patients undergoing coronary artery bypass grafting. The elderly, however, face higher surgical risks and have shorter life expectancy, and thus the use of internal thoracic artery grafting in this age group has been debated. This study examined the use, complication risks, and operative (30-day) mortality associated with internal thoracic artery grafting in patients 75 years of age and older.

Methods: Between 1996 and 1999, 522,656 patients in the Society of Thoracic Surgeons National Cardiac Database underwent primary, nonemergency-salvage coronary artery bypass grafting; of these, 99,942 were 75 years of age or older. The influence of internal thoracic artery use on operative mortality and 5 major complications in this elderly group was examined by means of (1) risk adjustment (adjusting for 28 baseline risk factors and site) and (2) a treatment propensity score analysis that compares patients with similar baseline likelihood for receiving an internal thoracic artery graft.

Results: In the National Cardiac Database $77.4 \%$ of patients aged 75 to 84 years received an internal thoracic artery graft compared with $93.5 \%$ for those aged 55 years or less. In this elderly group use of the internal thoracic artery was strongly associated with decreased operative mortality (unadjusted mortality, 6.20\% vs $4.05 \% ; P<.0001)$ that persisted after controlling for baseline risk and provider effects (adjusted odds ratio, 0.85; 95\% confidence intervals, 0.79-0.91). This mortality benefit was seen among those with low-to-high baseline propensity for receiving an internal thoracic artery graft.

Conclusions: Use of the internal thoracic artery in elderly patients undergoing coronary artery bypass grafting provides an acute survival benefit. This benefit is similar to that seen in younger patients and persists after adjusting for both patient and provider selection factors. The internal thoracic artery appears to be underused in elderly patients undergoing bypass grafting and is a potential area for quality improvement.

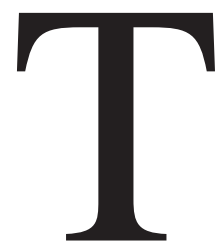

he procedure of coronary artery bypass grafting $(\mathrm{CABG})$ is the most examined intervention in medical history. Over the past 30 years, studies have addressed overall CABG outcomes versus those of alternative therapies, as well as the effect of technical improvements in the procedure itself. ${ }^{1-4}$ Among the most powerful of these technical improvements has been the grafting of the left internal thoracic artery (ITA) to the left anterior descending coronary artery (LAD). First introduced 
by Green, ${ }^{5}$ its efficacy was established in the seminal report by Loop and colleagues ${ }^{3}$ in 1986, demonstrating the beneficial long-term survival effect of ITA grafting. Subsequent studies established the superiority of the ITA versus the saphenous vein in terms of long-term patency. ${ }^{6}$

In 1994, the first report analyzing the effect of ITA grafting on acute (30-day) survival after CABG was published by Edwards and associates. ${ }^{7}$ Using the Society of Thoracic Surgeons (STS) National Cardiac Database (NCD) in an analysis of 38,578 patients, this study demonstrated that higher risk patients benefited from ITA grafting in terms of improved mortality. However, only $48 \%$ of patients in the NDB during this era (1987-1991) received an ITA graft, and only $15 \%$ were aged 75 years or older. Since then, the use of ITA grafting has increased significantly, ${ }^{8,9}$ and its use has become recognized as a marker of quality of care. ${ }^{10-13}$

Although few dispute the acute and long-term benefits of ITA grafting in younger patients undergoing $\mathrm{CABG}$, the risk versus benefit of ITA grafting in high-risk patients is less clear, as recently elucidated by Cohn. ${ }^{14}$ At the top of this high-risk list are the septuagenarians, octogenarians, and nonagenarians presenting for revascularization. ${ }^{15,16}$ Specifically, the elderly face higher mortality and postoperative complication risks, and it can be questioned whether any operative technique that might further increase these risks is worthwhile. Finally, because the elderly have a shorter natural life expectancy after CABG, some have questioned ITA use in this setting because the long-term survival benefits are less likely to be realized. As the mean age of patients undergoing CABG continues to increase, a reevaluation of ITA therapy in this subgroup seems warranted.

We therefore undertook this study to evaluate contemporary-era use of ITA grafting in the STS National Database. Because of the question of efficacy in the aged population (ie, $\geq 75$ years), we analyzed the use and complications associated with ITA grafting in this population.

\section{Methods}

\section{Data Collection}

STS NCD data are harvested semiannually from sites nationwide performing cardiac surgery. Through 1999, the Adult Cardiac Database contained 1.54 million patient records. Data are warehoused at the Duke Clinical Research Institute (DCRI) in Durham, NC, and the Outcomes Group at DCRI performs the statistical analyses for the reports and scientific investigations. Site-specific feedback reports are generated semiannually for the local participants for outcomes analysis and quality-improvement efforts. In addition, regional reports for state and regional groups around the country are produced for the purposes of regional quality-improvement activities.

\section{Study Population}

The study population was derived from the patients in the STS NCD who underwent isolated, first-time CABG between 1996 and 1999. Excluded were patients who had a concomitant valve or other cardiac procedures and patients undergoing reoperation. Also excluded were patients who presented for emergency or salvage intervention according to the STS definition because emergency or salvage status strongly affects the decision to use an ITA graft. Under emergency conditions, some patients are not eligible for ITA grafting, but variables in the NCD are not available to distinguish these patients from those who are eligible. Thus only elective and urgent cases were included in the analysis.

This study population data set was harvested from a total of 495 sites; there were 9 additional sites at which the ITA use was less than $40 \%$, and these sites were excluded from the analysis for data-quality reasons. Finally, patient records in which ITA grafting data were missing or the 2 ITA-related variables in the NCD data set were inconsistent were excluded as well. These latter 2 exclusions were for data-quality reasons.

\section{Statistical Methods}

The purpose of this analysis was to examine the effect of ITA grafting in the elderly on operative (30-day) mortality and on major morbidity categories of prolonged ventilation, mediastinitis, repeat surgical intervention (any reason), postoperative acute renal failure, and postoperative stroke. Because of the observational nature of the data, it was important to consider the possibility of confounding, namely that healthier patients may receive an ITA graft or that sites that more often use an ITA graft may focus on quality and generally have better outcomes. Either of these circumstances could cause the use of an ITA graft to appear to be more effective than it actually is. We used 2 statistical methods that account for both patient- and site-level confounding to evaluate the influence of ITA grafting.

Multivariate logistic analysis. First, a random-effects logistic model was used to test for the effect of ITA grafting on mortality and complications after adjusting for 28 baseline patient risk factors (of the total of 106 variables collected for an isolated $\mathrm{CABG}$ procedure), as well as site (as a random effect) and the percentage of ITA use at the site. Risk-adjusted odds ratios (ORs) with $95 \%$ confidence intervals (CIs) provide estimates of the within-site effect of ITA use. ${ }^{17,18}$

Patients were divided into 5 groups on the basis of their preoperative risk scores (obtained from risk-adjustment model with ITA excluded) to determine whether the effect varied according to patient risk, and mortality rates for patients receiving an ITA graft and those not receiving an ITA graft were calculated.

Finally, an analysis of interaction between ITA use and all other variables was also performed to determine whether the effect of ITA grafting remained constant across levels of the other variables.

Propensity score analysis. Second, a treatment propensity score analysis was performed. ${ }^{19}$ A random-effects logistic model that included both patient risk factors and a site 
effect was used to determine the propensity for receiving an ITA graft. ORs and 95\% CIs were generated for each variable included in the model. These variables encompass all the relevant risk factors in the STS CABG mortality model, which has been extensively validated. The same 28 variables used in the mortality model were used in the propensity model analysis because the bias caused by leaving out a weakly predictive confounding variable dominates the efficiency gained from not using that variable. ${ }^{20}$ The patients were then divided into 5 quintiles of equal size on the basis of their propensity scores. An overall test of the association of ITA grafting on mortality was performed by using the Mantel-Haenszel test.

In an additional step, patients were also matched on propensity score, and the effect of ITA grafting was examined in this pair-matched group.

\section{Survey Data}

A survey tool was developed and distributed to 495 respondent sites that participate in the NCD to assess the prevailing assumptions regarding ITA grafting in the elderly among practicing STS participants. This tool surveyed a site's opinion regarding ITA use in the elderly, consistency of this opinion with current practice, and a percentage estimate of patients older than 75 years who received an ITA graft at their institution.

\section{Results}

Through 1999, a total of $1,517,765$ patient records have been harvested into the Adult Cardiac Database of the STS. Between 1996 and 1999, a total of 687,112 patients who underwent isolated CABG of all preoperative status categories (elective, urgent, emergency, and salvage) were harvested. The 48,241 emergency or salvage patients were excluded, as were the 50,397 patients who had previously undergone a $\mathrm{CABG}$ procedure. After excluding sites at which the ITA use was less than $40 \%$, the data set contained 540,148 patients (106,075 age $\geq 75$ years); after excluding missing or conflicting ITA data, the final data set was comprised of 522,656 patients, with 99,942 patients 75 years or older.

\section{Use of ITA in the STS National Database}

During the study period for this analysis (1996-1999), ITA use reached a plateau at approximately $85 \%$ for the overall population compared with $48 \%$ in the earlier STS report from 1987 to $1991 .^{7}$ Use in the population 75 years or older has lagged behind that in the total population by about $10 \%$ to $15 \%$ annually during this time period.

Figure 1 shows ITA use by age group in the NCD for the study period. Of elective or urgent patients aged 20 to 54 years, $93.5 \%$ received an ITA. This use declined after age 74 years to only $57.8 \%$ in the 85 -year-old age group. In 1999 , the percentage of ITA use was $89.9 \%$ for the total

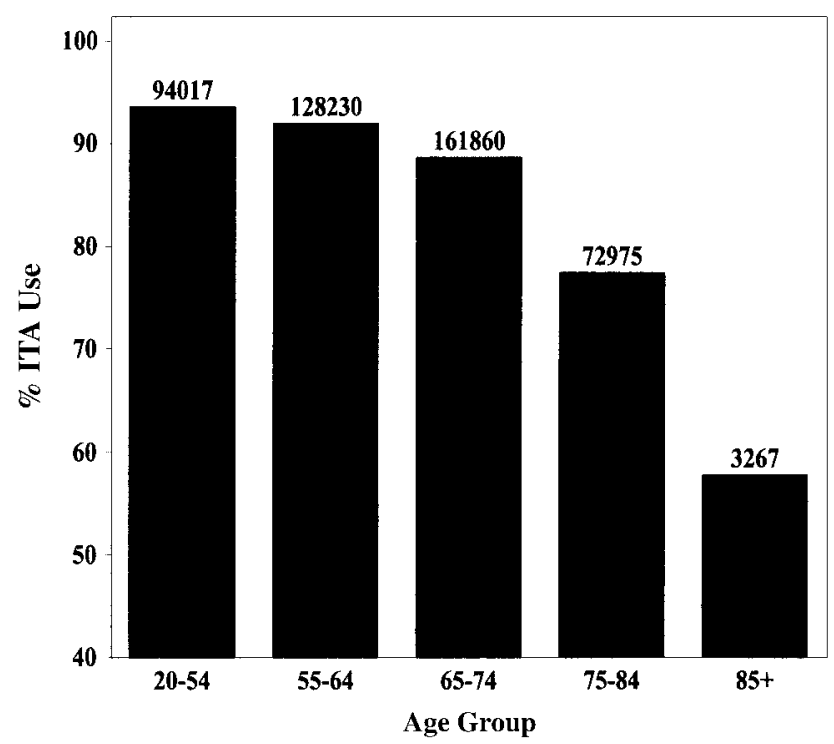

Figure 1. ITA use by age grouping in the STS NCD. The percentage of ITA use declines significantly after age 65 years. The numbers above the bars indicate the number of patients in that age group subset. Total numbers for these subgroups include the following: age 20-54 years, 94,017/100,520; 55-64 years, 128,230/139,512; 65-74 years, 161,860/182,682; 75-84 years, 72,975/94,287; and 85 years and older, $3267 / 5655$.

population and $80.8 \%$ for patients 75 years or older (compared with $77.4 \%$ for the 3 -year average).

The use of an ITA in the elderly varied considerably among the 495 sites included in this study. The 25th percentile, median, and 75th percentile of use of an ITA in this elderly population was $53 \%, 72 \%$, and $86 \%$, respectively.

\section{Risk Adjustment}

Table 1 shows the descriptive statistics comparing the 23,700 patients over age 75 years without ITA grafting with the 76,242 patients with ITA grafting. The univariate comparison differences were statistically significant for all variables except diabetes. The mean age of the population was 79 years, which is significantly older than any data set of this size previously reported. The group not receiving an ITA graft was older and had more women. This group also had a higher incidence of preoperative arrhythmias, preoperative shock and congestive heart failure, chronic lung disease, stroke, and preoperative dialysis and a slightly lower ejection fraction (EF). The incidence of preoperative intra-aortic balloon pumping and left main and triple-vessel disease was higher as well. There was also a higher incidence of patients coming to the surgical department classified as urgent preoperative status.

Table 2 shows unadjusted outcomes for mortality and major morbidity categories. Mortality before risk adjustment was higher in the group not receiving an ITA graft, as 
TABLE 1. Overall descriptive statistics for patients age 75 years or greater, STS National Database

\begin{tabular}{|c|c|c|c|c|c|}
\hline Variable & Data type & Level & $\begin{array}{c}\text { No ITA } \\
(n=23,700) \\
\end{array}$ & $\begin{array}{c}\text { ITA } \\
\text { (n= 76,242) }\end{array}$ & $P$ value \\
\hline \multirow[t]{4}{*}{ Age (y) } & Mean & & 79.63 & 78.27 & $<.0001$ \\
\hline & Median & & 79.00 & 78.00 & \\
\hline & 25th & & 77.00 & 76.00 & \\
\hline & 75th & & 82.00 & 80.00 & \\
\hline Arrhythmia & $\%$ & Yes & 20.73 & 17.36 & $<.0001$ \\
\hline \multirow[t]{4}{*}{ BSA } & Mean & & 1.79 & 1.84 & $<.0001$ \\
\hline & Median & & 1.81 & 1.86 & \\
\hline & 25th & & 1.66 & 1.72 & \\
\hline & 75th & & 1.95 & 2.00 & \\
\hline Cardiogenic shock & $\%$ & Yes & 2.43 & 1.50 & $<.0001$ \\
\hline $\mathrm{CHF}$ & $\%$ & Yes & 23.86 & 16.36 & $<.0001$ \\
\hline Chronic lung disease & $\%$ & Yes & 19.03 & 14.82 & $<.0001$ \\
\hline NYHA class IV & $\%$ & Yes & 27.16 & 22.99 & .0000 \\
\hline \multirow[t]{2}{*}{ CVA } & $\%$ & $>2 \mathrm{wk}$ & 10.34 & 8.72 & $<.0001$ \\
\hline & $\%$ & $<2$ wk & 0.42 & 0.31 & $<.0001$ \\
\hline CVD & $\%$ & Yes & 17.53 & 15.37 & $<.0001$ \\
\hline Diabetes & $\%$ & Yes & 27.91 & 27.93 & .9599 \\
\hline Dialysis & $\%$ & Yes & 1.04 & 0.58 & $<.0001$ \\
\hline Female & $\%$ & Yes & 47.59 & 36.86 & $<.0001$ \\
\hline \multirow[t]{4}{*}{$\mathrm{EF}$} & Mean & & 49.13 & 50.94 & \\
\hline & Median & & 50.00 & 50.00 & $<.0001$ \\
\hline & 25th & & 40.00 & 45.00 & \\
\hline & 75th & & 59.00 & 60.00 & \\
\hline Preoperative IABP & $\%$ & Yes & 6.44 & 3.78 & $<.0001$ \\
\hline Left main disease & $\%$ & Yes & 25.03 & 23.32 & $<.0001$ \\
\hline \multirow[t]{4}{*}{$\mathrm{MI}$} & $\%$ & $>21 d$ & 24.23 & 24.06 & $<.0001$ \\
\hline & $\%$ & $1-21 d$ & 24.89 & 21.17 & $<.0001$ \\
\hline & $\%$ & $<24 \mathrm{~h}$ & 1.33 & 0.84 & $<.0001$ \\
\hline & $\%$ & $<6 \mathrm{~h}$ & 0.66 & 0.32 & $<.0001$ \\
\hline PVD & $\%$ & Yes & 20.46 & 18.43 & $<.0001$ \\
\hline Race & $\%$ & Yes & 7.50 & 6.03 & $<.0001$ \\
\hline Renal failure & $\%$ & Yes & 7.69 & 5.55 & $<.0001$ \\
\hline Triple-vessel disease & $\%$ & Yes & 73.42 & 75.62 & $<.0001$ \\
\hline Urgent status & $\%$ & Yes & 39.10 & 35.12 & $<.0001$ \\
\hline
\end{tabular}

BSA, Body surface area; $C H F$, congestive heart failure; NYHA, New York Heart Association; CVA, cerebrovascular accident (stroke, permanent); CVD, cerebrovascular disease; IABP, intra-aortic balloon pump; $M I$, myocardial infarction; $P V D$, peripheral vascular disease.

TABLE 2. Unadjusted outcomes of mortality and 5 major morbidities after primary elective or urgent CABG for patients older than 75 years in the STS NDB, 1996-1999 $(\mathrm{n}=99,942)$

\begin{tabular}{lccc}
\hline Outcome & No ITA & ITA & Unadjusted OR (95\% CI) \\
\hline Mortality & 6.20 & 4.05 & $0.64(0.61-0.68)$ \\
Complications & & & $0.85(0.78-0.92)$ \\
$\quad$ Stroke, permanent (\%) & 3.24 & 7.08 & $0.68(0.64-0.71)$ \\
$\quad$ Prolonged ventilation (\%) & 10.11 & $0.82(0.78-0.87)$ \\
$\quad$ Reoperation for any reason (\%) & 7.42 & 6.18 & $0.79(0.74-0.83)$ \\
$\quad$ Renal failure (\%) & 6.82 & 5.44 & $1.28(1.05-1.55)$ \\
$\quad$ Deep sternum infection (\%) & 0.52 & 0.66 & $8(6-12)$ \\
Length of stay (median [25th-75th]) & $10(7-14)$ & $5(4-6)$ & \\
Postoperative length of stay (median [25th-75th]) & $7(5-9)$ & & \\
\hline
\end{tabular}

was the postoperative incidence of stroke, prolonged ventilation, reoperation for any reason, and renal failure. Deep sternal infection was higher in the ITA group, but the incidence was small $(0.52 \%$ in the group not receiving an
ITA graft vs $0.66 \%$ in the group receiving an ITA graft). Mean total length of stay and postoperative length of stay were also longer in the group not receiving an ITA. For unadjusted mortality and stroke, prolonged ventilation, re- 
TABLE 3. Risk-adjusted outcomes using logistic regression models: Risk-adjusted mortality and major postoperative morbidity for ITA grafting in the elderly (age $>75$ years, $\mathrm{n}=$ 99,942)

\begin{tabular}{lc}
\hline Outcome & Risk-adjusted 0R (95\% CI) \\
\hline Mortality & $0.85(0.79-0.91)$ \\
Complications & $0.98(0.90-1.08)$ \\
$\quad$ Stroke, permanent (\%) & $0.86(0.81-0.91)$ \\
Prolonged ventilation (\%) & $0.95(0.89-1.01)$ \\
Reoperation for any reason (\%) & $0.95(0.88-1.01)$ \\
Renal failure (\%) & $1.36(1.12-1.65)$ \\
\hline Deep sternum infection (\%) & \\
\hline
\end{tabular}

The analysis includes adjustment for the site effect, as described in the "Methods" section.

operation, and renal failure, the unadjusted OR and $95 \% \mathrm{CI}$ levels were below 1.0.

Table 3 illustrates the risk-adjusted outcomes, as determined by using the random-effects logistic model. Included in the model was a random site effect, as well as a variable indicating the percentage of ITA use at that site. ${ }^{17}$ Including these variables in the model allowed for estimation of the effect of ITA grafting after controlling for confounding caused by site. The presence of an ITA graft significantly improved 30-day survival and was associated with a significant decrease in prolonged ventilation in this elderly population of patients. The risk-adjusted ORs for reoperation, stroke, and renal failure were less than 1.0 but did not reach statistical significance. There was a significant increase in the risk-adjusted OR for deep sternal infection.

Patients were divided into 5 groups on the basis of their preoperative risk scores to determine whether the improvement in 30-day mortality varied according to preoperative patient risk class, and mortality rates for the groups receiving and not receiving an ITA graft were compared. These predicted risk scores were obtained from the risk model with ITA excluded. Figure 2 shows that mortality rates for those receiving an ITA were lower than rates for those not receiving an ITA in each of the 5 predicted risk groups.

An examination of potential interactions of ITA use with baseline risk variables yielded 2 significant interactions, namely for age and EF. In subgroup analysis (Figure 3) the acute survival benefits of an ITA graft appear to diminish in those aged 85 years or older. Subgroup analysis also demonstrated that as EF decreases, the benefit of ITA grafting on operative mortality declines as well; the patients with moderate $(30>\mathrm{EF}<45)$ and severe $(<30)$ dysfunction demonstrated a trend toward survival that did not achieve statistical significance.

\section{Propensity Score Analysis ${ }^{19}$}

A total of 29 variables were used to develop a propensity for receiving an ITA graft for each member of the population

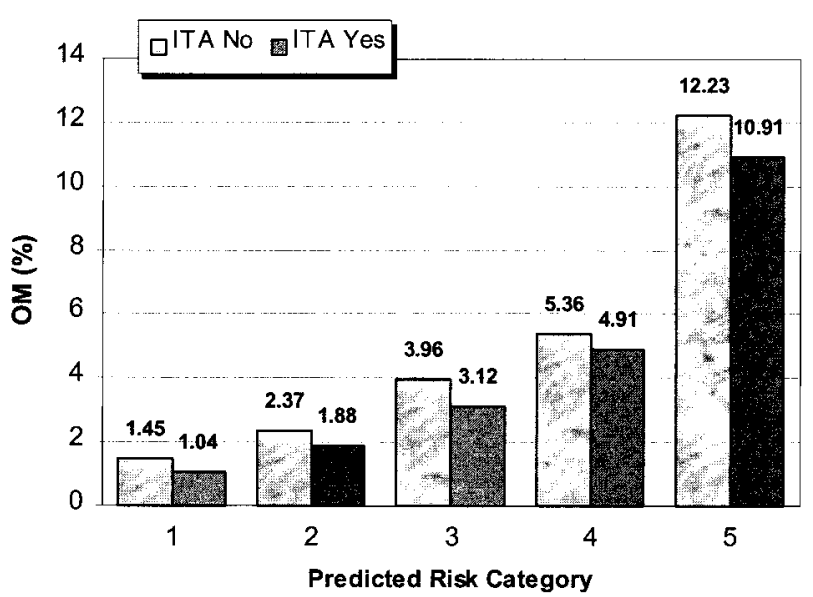

Figure 2. ITA use by preoperative risk group in patients 75 years of age and older. The 5 predicted risk groups were based on preoperative risk assessment in a model without ITA use as a variable. These data suggest that ITA grafting conveys a benefit in each of the 5 risk groups, including the lowest risk group. OM, Observed mortality.

75 years of age or older. The ORs, CIs, $t$ values, and $P$ values for these variables are shown in Table 4 and are sorted in order of their predictive power on the basis of the absolute value of $t$. Variables with a negative $t$ value contributed to a negative propensity for ITA use; among these were female sex, chronic lung disease, preoperative intraaortic balloon pumping, and preoperative congestive heart failure. Alternatively, the propensity for an ITA graft was increased by increased body surface area, better EF, and left main and triple-vessel disease. This propensity analysis included the adjustment for the site effect. ${ }^{17,18}$

Table 5 illustrates the grouping of the total population into quintiles on the basis of these assigned propensity scores. Patients who received an ITA graft were then compared with those who did not within each quintile. The lowest propensity score group had only $38.5 \%$ use of an ITA, whereas the highest propensity score group had a 97.8\% use rate.

For each propensity score group the mortality rates were lower in the group receiving an ITA graft. The overall association of ITA use and mortality in the propensity score analysis was highly significant $(P<.0001$, Mantel-Haenszel test). Within-group mortality differences ranged from 0.34 in the low-propensity group to 2.29 in the high-propensity group. Thus even in the group with the lowest propensity for ITA grafting preoperatively, an acute survival benefit was accrued by ITA grafting. Stated another way, there was no propensity score group that did not benefit from ITA grafting. The average difference in mortality was 1.29 across the 5 propensity groups.

The matched-pair analysis also demonstrated a benefit to ITA grafting. Importantly, there were only 220 patients of 
TABLE 4. Listing of variables used to develop propensity score for the propensity score analysis

\begin{tabular}{|c|c|c|c|c|c|}
\hline Variable & OR & $\begin{array}{l}\text { Lower } \\
95 \% \mathrm{CI}\end{array}$ & $\begin{array}{c}\text { Upper } \\
95 \% \text { CI }\end{array}$ & $t$ Value & $P$ value \\
\hline Participant & & & & & $<.0001$ \\
\hline Age & 0.86 & 0.86 & 0.87 & -55.77 & $<.0001$ \\
\hline Female sex & 0.69 & 0.66 & 0.72 & -17.31 & $<.0001$ \\
\hline Chronic lung & 0.69 & 0.66 & 0.72 & -16.05 & $<.0001$ \\
\hline BSA & 2.17 & 1.96 & 2.41 & 14.44 & $<.0001$ \\
\hline $\mathrm{EF}$ & 1.01 & 1.01 & 1.01 & 14.05 & $<.0001$ \\
\hline IABP & 0.65 & 0.60 & 0.70 & -10.67 & $<.0001$ \\
\hline $\mathrm{CHF}$ & 0.79 & 0.75 & 0.83 & -9.70 & $<.0001$ \\
\hline Triple-vessel disease & 1.19 & 1.14 & 1.24 & 8.52 & $<.0001$ \\
\hline Steroids & 0.71 & 0.65 & 0.77 & -7.87 & $<.0001$ \\
\hline First reoperation & 0.47 & 0.38 & 0.58 & -6.92 & $<.0001$ \\
\hline Nitrates & 0.88 & 0.84 & 0.91 & -6.08 & $<.0001$ \\
\hline Diuretics & 0.89 & 0.86 & 0.93 & -5.56 & $<.0001$ \\
\hline Urgent status & 0.89 & 0.85 & 0.93 & -5.40 & $<.0001$ \\
\hline $\mathrm{Ml}$ & 0.95 & 0.93 & 0.97 & -5.11 & $<.0001$ \\
\hline Arrhythmia & 0.90 & 0.86 & 0.94 & -4.81 & $<.0001$ \\
\hline CVA & 0.87 & 0.82 & 0.92 & -4.62 & $<.0001$ \\
\hline Shock & 0.76 & 0.67 & 0.86 & -4.41 & $<.0001$ \\
\hline Dialysis & 0.69 & 0.57 & 0.84 & -3.65 & .00 \\
\hline Digitalis & 0.91 & 0.87 & 0.96 & -3.60 & .00 \\
\hline Renal failure & 0.86 & 0.78 & 0.94 & -3.25 & .00 \\
\hline Race & 0.89 & 0.83 & 0.96 & -3.19 & .00 \\
\hline 2 or more reoperations & 0.34 & 0.15 & 0.77 & -2.58 & .01 \\
\hline CVD & 0.94 & 0.89 & 0.99 & -2.42 & .02 \\
\hline Diabetes & 0.95 & 0.92 & 0.99 & -2.41 & .02 \\
\hline PVD & 0.95 & 0.91 & 1.00 & -2.03 & .04 \\
\hline NYHA class IV & 0.97 & 0.92 & 1.01 & -1.50 & .13 \\
\hline Creatinine & 0.98 & 0.95 & 1.01 & -1.27 & .20 \\
\hline Left main disease & 1.00 & 0.96 & 1.04 & -0.13 & .90 \\
\hline
\end{tabular}

Negative $t$ values indicate a negative propensity for ITA grafting preoperatively. Positive $t$ values indicate a propensity for ITA grafting.

$B S A$, Body surface area; $I A B P$, intra-aortic balloon pump; $C H F$, congestive heart failure; $M I$, myocardial infarction; CVA, cerebrovascular accident (stroke, permanent); $C V D$, cerebrovascular disease; $P V D$, peripheral vascular disease; NYHA, New York Heart Association.

the total 99,942 patients that could not be matched to 0.01 . This analysis showed a strong benefit of ITA use versus not receiving an ITA (OR, 0.73; 95\% CI, 0.69-0.76).

\section{Discussion}

\section{The STS National Database}

This is the second report on the influence of ITA graft use on acute (30-day) mortality from the STS National Database. ${ }^{7}$ The present study documents that a significant survival benefit is accrued by means of routine ITA grafting in a patient population considerably older than any previously reported. These results are gratifyingly similar to those reported for younger patients.

\section{Benefits of ITA Grafting: Patency and Long-term Survival}

Improved late survival resulting from in situ left ITA grafting has been well documented through a number of large,
TABLE 5. Propensity score analysis

\begin{tabular}{cccccc}
\hline & & & \multicolumn{3}{c}{ Mortality rates } \\
\cline { 4 - 5 } Propensity score & Total patients & ITA (\%) & No ITA & ITA & $\Delta$ \\
\hline $0.01-0.59$ & 19,988 & 38.5 & 6.91 & 6.57 & 0.34 \\
$0.59-0.78$ & 19,989 & 69.1 & 5.48 & 4.65 & 0.83 \\
$0.78-0.88$ & 19,988 & 84.0 & 5.35 & 4.17 & 1.18 \\
$0.88-0.95$ & 19,989 & 92.0 & 5.52 & 3.69 & 1.83 \\
$0.95-1.0$ & 19,988 & 97.8 & 5.15 & 2.86 & 2.29 \\
\hline
\end{tabular}

After assigning a propensity score to all patients, patients were grouped by propensity score into 5 propensity score categories from low to high. Within each grouping, the mortality on the basis of whether the patient received an ITA was compared. All 5 categories demonstrated improvement in mortality with ITA grafting. Although the greatest benefit was seen in the patients with the highest propensity score (the greatest likelihood of receiving an ITA on the basis of preoperative variables), even the patients in the lowest propensity score grouping showed a protective effect of ITA grafting. The average difference in mortality rate was 1.29 Mantel-Haenszel test for association between mortality and ITA use: $P<.0001$.

single-institution analyses. ${ }^{3,5,6}$ The mechanism for this improved patency is thought to relate to the arterial nature of the conduit with its associated biochemical and physiologic characteristics absent in venous conduits, the in situ nature of the graft with only a single (distal) anastomosis, the more anatomic size match between the conduit and the recipient native coronary artery, ${ }^{14,21}$ and the relative lack of propensity for development of atherosclerotic arterial disease..$^{5,22,23}$

In one of these studies, Lytle and colleagues ${ }^{24}$ concluded that bilateral ITA grafting conveys an additional benefit over single ITA grafting in terms of late (12-year) mortality, freedom from reoperation, and percutaneous transluminal coronary angioplasty intervention. Bilateral grafting improved survival over single ITA grafting, even in the subgroup that was more elderly at the time of the operation. In an accompanying analysis of the same data set, Blackstone and Lytle ${ }^{25}$ demonstrated that the late death incidence after either single or bilateral ITA grafting increases with the age at the nascent operation. However, only $3.1 \%$ of patients receiving bilateral ITA grafts and $11.0 \%$ of patients receiving single ITA grafts in this analysis were older than 70 years at the time of initial surgical intervention in this data set.

Few, if any, other studies contain significant numbers of elderly patients (as defined in this analysis), and long-term survival was not a focus of the present study. Thus the importance of long-term survival in considering the use of an ITA graft in elderly patients undergoing CABG remains unclear. Many surgeons have foregone ITA grafting in these patients on the presumption that this long-term benefit might never be realized. However, it would be surprising if the findings from younger patients could not be extrapolated to older patient subsets, particularly those in the 75- to 80 -year age group without associated disease processes. The percentage of elderly patients presenting for revasculariza- 


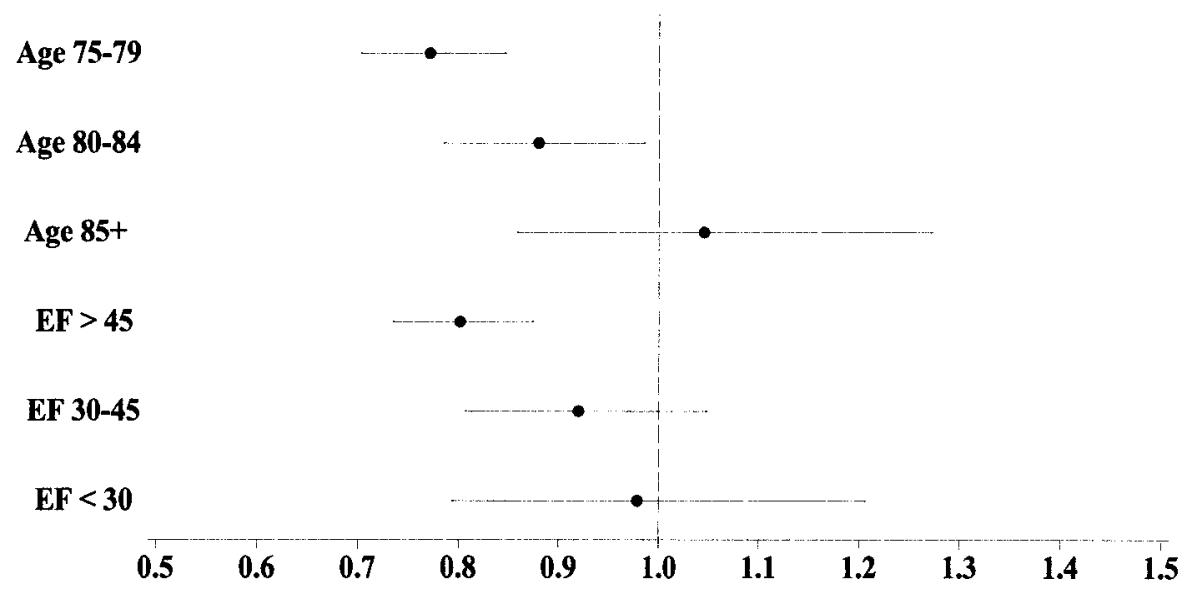

Figure 3. Multivariable logistic regression analysis of interaction. ITA use interacted significantly with age and EF. Data are expressed as OR of survival with $95 \%$ Cls. A value of less than 1.0 indicates a beneficial effect of ITA grafting on survival for that subset. For age, patient numbers include the following: age 75-79 years, 67,643; 80-84 years, 26,644; and 85 years and older, 5655. For $E F$, patient numbers include the following: $E F 45$ and higher, 74,691; 30-45, 20,148; and less than 30, 5103.

ton continues to increase; from 1990 to 1999 , the mean age of patients presenting for surgical intervention in the STS NCD increased from 65.2 to 66.7 years $(P<.0001)$, and the percentage of patients older than 75 years increased by $3.4 \% .15$

\section{Benefits of ITA Grafting: Acute Mortality}

The effect of ITA grafting on acute (in-hospital or 30-day) mortality is more clearly understood. Cosgrove and colleagues, ${ }^{26}$ in 1986, documented that the use of ITA grafting did not increase operative mortality. Gardner and coworkers $^{27}$ reported, in 1990, on the safety and efficacy of ITA grafting in an elderly (defined as $>70$ years of age) population from a single institution. Beginning in 1994, documentation of an improved acute survival benefit from ITA grafting was demonstrated from voluntary (STS) and compulsory (VA) databases. ${ }^{7,9}$ Recently, Sergeant and associates ${ }^{28}$ could not demonstrate any influence of single, multiple, sequential, or complete arterial revascularization on early survival after CABG for reasons thought to be related to the unique European data set. In the Lytle studies ${ }^{24,25}$ the early hazard phase comparing the 2 arterial grafting strategies demonstrated that ITA grafting to the LAD conveyed an acute (in-hospital) survival benefit; female sex, age, left ventricular dysfunction, and peripheral vascular disease increased the early hazard risk of death.

Data from this study demonstrate for the first time similar beneficial results in a substantial population of patients 75 years or older. A $40 \%$ decrease in unadjusted mortality was seen (Table 2), along with a significant decline in risk-adjusted mortality, by using analyses that account for the patient selection and site effects that can confound observational data set analyses (Tables 3 and 5).
In Table 1, 24\% of patients had left main disease of greater than $50 \%$, and $73 \%$ had three-vessel disease. Thus the number of patients who were revascularized without a left ITA graft to the LAD because of the absence of anatomic disease in the LAD was small, and in most cases the lack of ITA grafting was due to physician choice and not anatomically based. By means of univariate analysis (Table 1), the group not undergoing ITA grafting appeared to be at higher risk on the basis of preoperative risk factor variables and had a higher incidence of risk factors that could potentially contribute to complications related to ITA grafting, namely congestive heart failure, chronic lung disease, preoperative renal failure-dialysis, left main disease $(>50 \%)$, and urgent operative status. Each of these conditions might dissuade a surgeon from electing to perform an ITA graft in a selected patient. The present study suggests, however, that ITA grafting should be used in these patients for the acute perioperative mortality benefit.

\section{Patient Subgroups Associated With ITA Grafting in the Elderly}

In Figure 2 all 5 predicted risk subgroups (low to high risk) showed a trend toward improvement in mortality in the ITA group. These data suggest that ITA grafting in the elderly conveys an acute survival advantage across all levels of preoperative risk. These results are consistent with prior analyses by Edwards and colleagues ${ }^{7}$ and the Northern New England Cardiovascular Study group ${ }^{29}$ in younger patient groups. The relative risk reduction conveyed by ITA use is less in the elderly than that reported previously in younger patients; however, given that elderly patients have a higher baseline risk, the absolute risk reduction is similar or greater in magnitude in the elderly. 
The analysis of interaction between ITA grafting and other variables yielded 2 interactions that were significant, namely age and EF. Both increasing age and decreasing EF are independently associated with an overall mortality increase after CABG.1,3,4,16 Figure 3 illustrates, in a format useful for clinicians, that the survival benefit of ITA grafting declines with increasing age at operation and with decreasing preoperative EF. Clinicians are cautioned, however, that these are post hoc subgroup analyses and should be viewed in the context of the overall survival benefit demonstrated for this population. Confirmation of these subgroup findings in other databases is suggested. Also, this analysis examined only acute mortality benefits, and these groups may still have long-term benefits from ITA.

\section{Perioperative Complications}

Use of the ITA graft was also generally not associated with an overall increase in perioperative morbidity risk in this elderly population. Of the 5 major complication end points used in the STS risk-assessment model shown in Table 3, prolonged ventilation was decreased significantly compared with that seen in the group not receiving an ITA graft, and the incidences of stroke, reoperation, and renal failure were not statistically different and, importantly, were not increased. The incidence of mediastinitis in the group receiving an ITA graft was significantly increased, however, and thus the relative risk was higher in the this group. However, the absolute risk in the group receiving an ITA graft was still less than $1.0 \%$ (Table 2), which was actually less than in the NCD as a whole for this time interval ${ }^{15}$ and was less than that reported by Lytle and colleagues ${ }^{24}$ and less than the Northern New England Cardiovascular Study Group (NNE) reported, ${ }^{29,30}$ despite the significantly older population in this STS analysis. Thus the potential for complications should not a priori dissuade surgeons from the use of ITA grafts in this elderly patient population.

\section{Propensity Score Analysis}

The propensity score analysis we performed demonstrated that in each of 5 quintiles of patients, ranging from low to high propensity for receiving an ITA graft on the basis of preoperative variables, the use of an ITA graft also had a protective effect compared with that seen patients in that quintile group who did not receive an ITA graft. The magnitude of benefit increased with the increasing propensity to use an ITA graft, as would be expected; however, even in the lowest propensity quintile group ITA grafting was of benefit. Similarly, a matched-pairs analysis (matching patients with similar baseline likelihood for getting an ITA) found that those who actually received an ITA had significantly lower risk for acute mortality (OR, $0.73 ; 95 \% \mathrm{CI}$, 0.69-0.76). Importantly, this study documented that even elderly patients who, on the basis of preoperative risk factors, would least likely be considered candidates for an ITA graft derive a survival benefit from use of this arterial conduit. As such, age alone should not exclude patients from consideration for ITA grafting.

\section{Quality of Care Implications}

Figure 1 and the survey data (see Appendix) suggest that in the STS NCD, ITA grafting in elderly patients may be underused compared with younger patients. Although ITA use over the past 5 years has increased in the elderly population parallel to that seen in the overall $\mathrm{NCD}$, the rate of use remains some $10 \%$ to $15 \%$ less. In addition, a wide distribution of ITA use exists among the almost 500 sites that participated in the NCD in this contemporary time frame. Variance between a site's perceptions about their practices and the actual use data were documented in the survey. A mean estimate of $83.3 \%$ was given as the percentage use of ITA at their site compared with the $77.4 \%$ documented in this analysis. In addition, over one fifth of sites reported the sentiment that ITA grafting in the elderly was not beneficial.

These results parallel earlier observations from the NNE group $^{30}$ and the Alabama Quality Assurance Foundation CABG Cooperative Project ${ }^{11}$ that there can be widespread variability in use of the ITA as a conduit between centers. Importantly, both the NNE and Alabama Quality Assurance Foundation projects identified ITA grafting as a process of care suitable for quality improvement bench marking, and both have demonstrated significant increases in ITA use in their patient populations..$^{29,31}$

Taken together, Figure 1 and the survey data suggest that additional justification for the use of the ITA in these elderly patients will be necessary to change physician behavior. The beneficial effect on operative survival (at least in patients $\leq 85$ years) in the absence of a significant risk of increased complications demonstrated in the present study may provide that additional justification.

ITA grafting thus should be considered for use as a quality indicator in patients of all ages undergoing CABG. As a process measure, it has the advantage that it is well standardized and is a discrete component of the surgical procedure. Moreover, the decision to use or not to use an ITA in these elderly patients is almost solely the responsibility of the operating surgeon. This focuses the associated quality-improvement efforts at the surgeon as an individual practitioner and to all cardiac surgeons as a group through the STS NCD. This greatly facilitates the mechanisms by which the specific behavior regarding this process of care and the beneficial effect on these patients can be positively influenced. ${ }^{32}$ Table 4 provided insight to the preoperative risk factors on which physician bias for or against ITA use may be based.

\section{Possible Mechanism of Benefit}

The reasons for the improvement in acute survival of ITA grafting (for all ages) remain unclear. However, there are 
several possible explanations applicable to this elderly population. The quality of the greater saphenous vein may be less than in a younger patient, which in turn may lead to a decreased incidence of early graft failure caused by thrombotic complications. Decreasing the number of proximal anastomoses might also be beneficial in elderly patients with aortic disease. The important physiologic benefits of an arterial graft may also contribute to early graft patency in senescent and often calcified coronary arterial trees and under conditions of extensive distal disease, where complete revascularization may be less technically feasible. ${ }^{22,33}$ Finally, given the greater than $90 \%$ use of ITA grafting to the anterior heart in younger patients, surgeons may be performing a different operation when they attempt to graft a saphenous vein graft to the LAD in the elderly.

\section{Limitations}

This study was a nationwide, multisite observational study. One criticism of observational studies is that patients who receive an intervention (that is shown to be beneficial) are not as high risk as those who do not. Moreover, multisite observational studies should control for the confounding because of between-site effects as well. Both issues have been addressed in the statistical analyses in this study.

In addition, the study is limited by the nature of large, multisite voluntary databases. Recent studies, however, have documented that the data quality in the NCD is similar to that in other mandatory database efforts in cardiovascular surgical disease. ${ }^{12,15}$ The study is also limited by the relatively small number of patients in the older than 85-year subgroup; we will continue to follow this group of patients closely as more and more of them present for surgical intervention in the next few years.

Elderly patients presenting for CABG under emergencysalvage circumstances were excluded from this analysis, and conclusions about the benefits of ITA grafting should probably not be extended to this subgroup.

Finally, this study focused only on the acute (30-day) survival benefit of ITA grafting. Although it may be possible to extrapolate the long-term benefits seen in younger patients to this elderly group, this requires further confirmation.

\section{Conclusions}

We found a similar acute survival advantage among very elderly patients, as has previously been demonstrated among younger patients presenting for elective or urgent CABG. This benefit can be realized without a substantial increased risk of perioperative complications. Thus surgeons should strongly consider use of an ITA graft to the LAD in all patients presenting for elective or urgent revascularization, regardless of age.

We also found that ITA grafting is underused in the elderly. The number of elderly patients coming to surgical revascularization will continue to increase, ${ }^{15}$ and therefore an improvement in overall CABG quality of care could be realized through the incorporation of this process of care into routine practice. The STS National Database provides an opportunity to track this process of care over time and can provide feedback to physicians to ensure evidencebased care practices are provided to all patients.

We thank the Society of Thoracic Surgeons Office of Research and Meghan Carey and Mary Eiken for their Project Management of the Society's AHRQ grant. Similarly, we thank Nancy Sinreich at the Duke Clinical Research Institute for her Project Management support for this grant. Finally, we thank Elizabeth R. Delong, PhD, of the DCRI for her advice on the statistical treatment of this patient data set.

\section{References}

1. Favaloro RG. Critical analysis of coronary artery bypass surgery: a 30-year journey. J Am Coll Cardiol. 1998;31:1B-63B.

2. Coronary Artery Surgery Study (CASS) principal investigators and associates. A randomized trial of coronary artery bypass surgery: survival data. Circulation. 1983;68:939-50.

3. Loop FD, Lytle BD, Cosgrove DM, et al. Influence of the internal mammary artery graft on 10-year survival and other cardiac events. N Engl J Med. 1986;314:1-6.

4. Brooks MM, Jones RH, Bach RG, et al. Predictors of mortality and mortality from cardiac causes in the bypass angioplasty revascularization investigation (BARI) randomized trial and registry. For the BARI Investigators. Circulation. 2000;101:2682-9.

5. Green GE. Internal mammary artery-to-coronary artery anastomosis: three year experience with 165 patients. Ann Thorac Surg. 1972;14: 260-71.

6. Lytle BD, Loop FD, Cosgrove DM, et al. Long-term (5 to 12 years) serial studies of internal mammary artery and saphenous vein coronary bypass grafts. J Thorac Cardiovasc Surg. 1985;89:248-58.

7. Edwards FH, Clark RE, Schwartz M. Impact of internal mammary artery conduits on operative mortality in coronary revascularization. Ann Thorac Surg. 1994;57:27-32.

8. Cameron AAC, Davis KB, Green GE, et al. Coronary bypass surgery with internal thoracic artery grafts: effects on survival over a 15 year period. N Engl J Med. 1996;334:216-9.

9. Grover FL, Johnson RR, Marshall G, et al. Impact of mammary grafts on coronary bypass operative mortality and morbidity: Department of Veterans Affairs Cardiac Surgeons. Ann Thorac Surg. 1994;57:559-68.

10. O'Connor GT, Plume SK, Olmstead EM, et al. A regional intervention to improve in hospital mortality associated with coronary artery bypass graft surgery: the Northern New England Cardiovascular Disease Study Group. JAMA. 1996;275:841-6.

11. Holman WL, Peterson ED, Athanasuleas CL, et al. Alabama Coronary Artery Bypass Grafting Cooperative Project: baseline data. Ann Thorac Surg. 1999;68:1592-8.

12. Ferguson TB Jr, Dziuban SW, Edwards FH, et al. The STS National Database: current changes and challenges for the new millennium. Ann Thorac Surg. 2000;69:680-91.

13. Arom KT, Peterson RJ, Orszulak TA, et al. Establishing and using a local/regional Cardiac Surgery Database. Ann Thorac Surg. 1997;64: 1245-9.

14. Cohn LH. Use of the internal mammary artery graft and in hospital mortality and other adverse outcomes associated with coronary artery bypass surgery. Circulation. 2001;102:483-4.

15. Ferguson TB Jr, Hammill B, Peterson ED, DeLong ER, Grover FL. A decade of change: risk profiles and outcomes for isolated CABG procedures, 1990-1999. Ann Thorac Surg. 2002;73:480-90.

16. Ko W, Gold JP, Lazzaro R, et al. Survival analysis of octogenarian patients with coronary artery disease managed by elective coronary bypass surgery vs. conventional medical treatment. Circulation. 1992; 86:II191-7. 
17. Neuhaus J, Kalbfleisch JD. Between- and within-cluster covariate effects in the analysis of clustered data. Biometrics. 1998;54:638-45.

18. Berlin JA, Kimmel SE, Ten Have TR, Sammel MD. An empirical comparison of several clustered data approaches under confounding due to cluster effects in the analysis of complications of coronary angiography. Biometrics. 1999;55:470-6.

19. Rosenbaum PR, Rubin DB. Reducing bias in observational studies using subclassification on the propensity score. J Am Stat Assoc. 1984;79:516-24.

20. Rubin DB, Thomas N. Matching used estimated propensity scores: Relating theory to practice. Biometrics. 1996;52:249-64.

21. Motwani JG, Topol EJ. Aortocoronary saphenous vein graft disease: pathogenesis, predisposition, and prevention. Circulation. 1998;97: 916-31.

22. Barner HB, Standeven JW, Reese J. Twelve year experience with internal mammary artery for coronary artery bypass. J Thorac Cardiovasc Surg. 1985;90:668-75.

23. Dignan RJ, Yeh T, Dyke CM, et al. The influence of age and sex on human internal mammary artery size and reactivity. Ann Thorac Surg. 1992;53:792-7.

24. Lytle BW, Blackstone EH, Loop FD, et al. Two internal thoracic artery grafts are better than one. J Thorac Cardiovasc Surg. 1999;117: 855-72.

25. Blackstone EH, Lytle BW. Competing risks after coronary bypass surgery: the influence of death on reintervention. J Thorac Cardiovasc Surg. 2000;119:1221-32.
26. Cosgrove DM, Loop FD, Lytle BD, et al. Does mammary artery grafting increase surgical risk? Circulation. 1985;72:II170-4.

27. Gardner TJ, Greene PS, Rykiel MF, et al. Routine use of the left internal mammary artery graft in the elderly. Ann Thorac Surg. 1990; 49:188-94.

28. Sergeant P, Blackstone E, Meyns B. Validation and interdependence with patient-variables of the influence of procedural variables on early and late survival after CABG: KU Leuven Coronary Surgery Program. Eur J Cardiothorac Surg. 1997;12:1-19.

29. Leavitt BJ, O'Connor GT, Olmstead EM, et al. Use of the internal mammary artery graft and in-hospital mortality and other adverse outcomes associated with coronary artery bypass surgery. Circulation. 2001;103:507-12.

30. Leavitt BJ, Olmstead EM, Plume SK, et al. Use of the internal mammary artery graft in Northern New England: the Northern New England Cardiovascular Disease Study Group. Circulation. 1997;96:II32-6.

31. Holman WL, Allman RM, Sansom M, et al. Alabama Coronary Artery Bypass Grafting (CABG) Project: results of a statewide quality improvement initiative. JAMA. 2001;285:3003-10.

32. Soumerai SB, McLaughlin TJ, Gurwith JH, et al. Effect of local medical opinion leaders on quality of care for acute myocardial infarction. JAMA. 1998;279:1358-63.

33. O'Connor NJ, Morton JR, Birkmeyer JD, et al. Effect of coronary artery diameter in patients undergoing coronary bypass surgery: the Northern New England Cardiovascular Disease Study Group. Circulation. 1996;93:652-5.

\section{APPENDIX I: Survey Data}

Sites Surveyed: Year 2000: $\quad N=495$

Surgical Technique: Bypass Conduits

1. ITA grafting decreases perioperative surgical risk even in elderly patients ( $>75$ years).

a. This statement is supported by the clinical literature.

$\square$ Strongly Disagree $\square$ Disagree $\square$ Agree $\square$ Strongly Agree $\square$ No Opinion

\begin{tabular}{lrrrr} 
q1A & Frequency & Percent & $\begin{array}{c}\text { Cumulative } \\
\text { Frequency }\end{array}$ & $\begin{array}{c}\text { Cumulative } \\
\text { Percent }\end{array}$ \\
\hdashline 1 = Strongly Disagree & 17 & 3.53 & 17 & 3.53 \\
2 = Disagree & 88 & 18.30 & 105 & 21.83 \\
3 = No Opinion & 22 & 4.57 & 127 & 26.40 \\
4 = Agree & 199 & 41.37 & 326 & 67.78 \\
$5=$ Strongly Agree & 155 & 32.22 & 481 & 100.00 \\
& Frequency Missing $=9$
\end{tabular}

b. This statement is consistent with my current clinical practice.

$\square$ Strongly Disagree $\square$ Disagree $\square$ Agree $\square$ Strongly Agree $\square$ No Opinion

$\begin{array}{lcccc}\text { q1B } & \text { Frequency } & \text { Pexcent } & \begin{array}{c}\text { Cumulative } \\ \text { Frequency }\end{array} & \begin{array}{c}\text { Cumulative } \\ \text { Percent }\end{array} \\ 1 \text { = Strongly Disagree } & 18 & 3.78 & 18 & 3.78 \\ 2 \text { = Disagree } & 72 & 15.13 & 90 & 18.91 \\ 3 \text { = No Opinion } & 14 & 2.94 & 104 & 21.85 \\ 4 \text { = Agree } & 171 & 35.92 & 275 & 57.77 \\ 5=\text { Strongly Agree } & 201 & 42.23 & 476 & 100.00 \\ & & \end{array}$

c. In my hospital, I estimate that $\%$ of CABG patients $>75$ years receive ITA grafting.

\begin{tabular}{|c|c|c|c|c|}
\hline $\mathrm{N}$ & Mean & Std Dev & Minimum & Maximum \\
\hline 77 & 83.3144654 & 17.2016482 & 2.0000000 & 100.0000000 \\
\hline
\end{tabular}



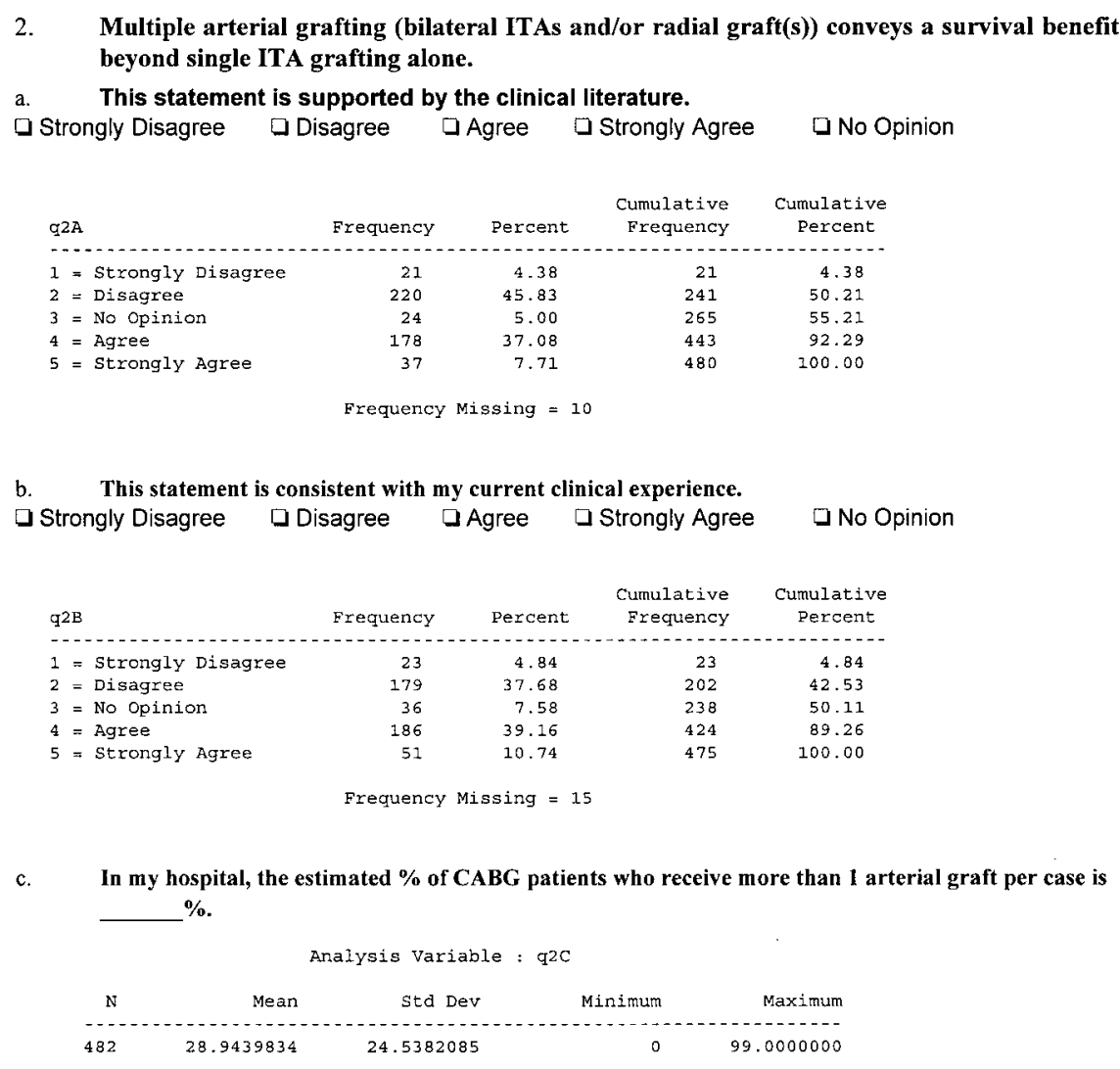

\section{Discussion}

Dr Timothy J. Gardner (Philadelphia, $\mathrm{Pa}$ ). First, let me compliment Dr Ferguson for an excellent presentation and for a very sophisticated review, which puts the STS database to perhaps its most valuable use, namely subspecialty-wide quality-improvement purposes. The National Cardiac Surgery Database, which was envisioned, planned, implemented, and nurtured by some of the most dedicated members of the STS, as well as supported financially by the Society during its initial development and subsequent rescue from Summit Medical's failure, has become an extremely valuable resource both for our specialty and for our patients.

The Federal Agency for Health Care Research and Quality's funding for the STS Database Committee under Bruce Ferguson's direction is really unique in medicine and carries with it the expectation that such a specialty-initiated project as this one will result in improvement in patient care broadly.

When I had the opportunity to address the Senate Appropriations Committee and the President's Bipartisan Commission on Medicare Reform in 1998 to argue against cuts in Medicare program support for cardiothoracic surgery, we were able to point to this unique specialty database as evidence of thoracic surgeons' commitment to quality improvement in the care of our Medicare patients.

Now, it goes without saying that information and its analysisappropriate analysis - are empowering, and this study provides an exemplary illustration of this fact. As Dr Ferguson mentioned, we thought we noted a possible survival benefit in our elderly patients receiving ITA grafts about 10 years ago, but our series was relatively small, and we could not eliminate the possibly confounding influence of patient selection bias on the results and on our conclusions.

In this present analysis, which relies on large numbers of patients from multiple centers and uses detailed and sophisticated preoperative risk stratification, the conclusion about the benefit of ITA use on patient survival, regardless of patient risk class, is compellingly clear. As in previous studies looking at younger patients, this analysis demonstrated the early and late survival benefit conferred by in situ ITA grafting of the LAD in patients 75 years or older. Can it be any clearer than this? Whenever an ITA graft is used, the recipient, even an elderly patient, is more likely to survive the operation.

Bruce, I would like to emphasize a couple of observations made here and ask a question. First, the incidence of prolonged postoperative ventilation in the elderly ITA graft population was actually lower than that seen in the no-ITA-graft patients. And I am sure others have occasionally avoided ITA use in patients with severe preoperative respiratory insufficiency or chronic obstructive pulmonary disease, assuming that ITA harvest and left pleural entry might increase the likelihood of difficulty weaning the patient from the ventilator. This was apparently not the case in these patients, and I wonder if you have any comments on that.

Second, there was, on the other hand, a significantly higher incidence of deep sternal wound infection in the ITA-harvested 
patients, although you point out that it was statistically significant but not a high occurrence rate. Do you believe that there are surgical techniques that ought to be considered in elderly patients having ITA takedown that might reduce the likelihood of sternal infection, such as a shorter segment of ITA harvest or whatever?

Lastly, you stated in the article, and you said again here, that ITA grafting could and perhaps should be used as a quality indicator in our review of our experience with patients undergoing CABG. Would you elaborate on how such an analysis can and should be made, and would you perhaps suggest what percentage of ITA use would be considered an appropriate quality indicator?

Dr Ferguson. Thank you very much, Dr. Gardner, for your nice comments, and, again, it was your study published from Hopkins 10 years ago that really introduced the concept of doing ITA grafting in the elderly population. Unfortunately, they continue to get older, and we continue to operate on them.

The incidence of prolonged ventilation was actually shorter in the ITA group. It is of interest that this is also true if one looks at the entire STS national data set and also other large data sets, including Northern New England. We all have a presumption that patients with severe chronic obstructive pulmonary disease would probably not do as well if we took an ITA graft. But at least the data that are out there from these large data sets do not seem to bear that out.

With regard to the deep sternal infection, that was obviously the only negative finding in this study. The good news is that the incidence still remains well below $1 \%$, but I think we have to say that in elderly patients harvesting an ITA may result in a slightly increased incidence of deep sternal infection. I think taking a shorter pedicle and using particular techniques of trying to avoid as much electrocautery of the sternum in these fragile patients who have very fragile tissues is a wise surgical approach to take.

We did not analyze the use of bilateral ITA grafting in this patient subset, so I cannot comment on that.

Finally, you mentioned the issue of quality improvement and using ITA grafting as a quality improvement indicator. This has been done in a number of regional settings, such as the Alabama Quality Assurance Foundation studies led by Dr Bill Homan and others. This STS effort is the first to attempt to demonstrate this on a national level.

As I mentioned, ITA grafting is a very important process measure because the surgeon decides whether to do an ITA graft. So if we are going to accept the fact that ITA grafting is beneficial for the operative mortality of a particular patient, then it is the surgeon-and only the surgeon in this case-who really needs to be convinced of that. If we look at the fact that $26 \%$ of the surgical sites surveyed say they did not think ITA grafting was going to be beneficial, those are the $26 \%$ whose preconceptions we need to change. They need to become convinced how this technique could be used as a mechanism to actually improve outcomes, in that if we do more ITA grafting in elderly patients, their operative mortality will go down.
Dr Bruce J. Leavitt (Burlington, Vt). This article discusses the use of the ITA graft as a conduit for CABG in the elderly patient population. This is the second reported study of ITA use in elderly patients having CABG. The Northern New England Cardiovascular Study Group, or NNE, recently reported that the use of the left ITA graft improved hospital mortality in patients undergoing bypass surgery. The protective effect was seen in all groups of patients and especially noted in the patients who were over 70 years of age. Our study included those patients having emergency surgical revascularization, which was $7 \%$ of the total, and in our calculations there was a $70 \%$ reduction of perioperative mortality in those patients who received an ITA graft.

Also in our study, $4 \%$ of the patients received bilateral ITA grafts or a right ITA graft. In your study these patients were excluded. The risk of mediastinitis was low but significantly increased in your study. We found a trend toward a lower rate of mediastinitis in any group, but this was based on our entire population and not just those older than 70 years. Dr Ferguson, looking at your data, it does appear that even though the use of ITA in the elderly is low, the greatest room for improvement in the ITA use is in groups that are over 70 years of age.

I have 3 points and 4 questions.

First, this article confirms our findings that the presence of an ITA graft is protective for a reduction in in-hospital mortality. Do you believe there is room for process improvement in all age groups, specifically in regard to ITA use? Second, why were emergency patients left out? We found a significant benefit in those groups. Third, did you consider the use of bilateral ITA or right ITA grafts in your study? And fourth, did you look at the trends of ITA use over time, and were there any changes in mortality during that period?

Dr Ferguson. Thanks, Bruce. I would like to congratulate the Northern New England group for having challenged us, and I think we have developed a very, very excellent collaborative relationship with them.

With regard to your questions, we excluded emergency cases because of the difficulty in the categorization of these cases and the presumption that that would, for the purposes of this analysis, make it more difficult to convey the message we were hoping to convey.

ITA grafting is a process-improvement tool. It has been used in all age groups. In younger patients use rates are currently $90 \%$ in the STS, $90 \%$ in Northern New England, and 90\% in this age population in the State of Alabama. The question in this subset is why is it not $100 \%$ ?

We did not do an analysis of bilateral ITA grafting. We have done an analysis of trends over time, in large part because of some earlier Northern New England reports. The actual incidence of ITA grafting overall in the national database has increased from $49 \%$ at the time of the Edwards publication in 1994 to $84 \%$ in this most recent analysis. So we have understood the message partially. We just have not understood it completely. 